\title{
ESCRITURAS DEL YO, ESCRITURAS DE LA NACIÓN: FACEBOOK, LITERATURA Y ACTIVISMO EN YOLANDA ARROYO PIZARRO
}

\author{
Paula Fernández Hernández \\ Grupo de investigación de pensamiento decolonial, Universidad de La Laguna \\ fdezhdezpaula@gmail.com
}

\section{RESUMEN}

Yolanda Arroyo Pizarro es una reconocida escritora puertorriqueña y activista por los derechos de las comunidades LGBTI y afrodescendientes. Su obra literaria se centra en retratar las subjetividades cuir y en celebrar la afroidentidad. En este artículo vinculo las distintas arenas en las que la autora refrenda su compromiso político con las comunidades vulnerables para proponer nuevas lecturas del género autobiográfico, que tienen en cuenta plataformas de construcción del yo tan paradigmáticas como Facebook. Esta estrategia, a su vez, entra en coherencia con los propósitos de la autora fundados en la creación de redes de apoyo entre grupos excluidos y en la descolonización profunda. De manera que análisis y visibilización de distintas formas de representación de cuerpos y subjetividades se unen en un estudio que, en última instancia, cuestiona los parámetros en los que se asientan instituciones tan emparentadas como escritura, género y nación.

Palabras Clave: autobiografía, cuir, afroidentidad, red social, descolonialidad.

\section{SELF-WRITINGS, NATION WRITINGS: FACEBOOK, LITERATURE, AND ACTIVISM IN YOLANDA ARROYO PIZARRO}

\section{Abstract}

Yolanda Arroyo Pizarro is a renowned Puerto Rican writer and activist for LGBTI rights and Afro-Caribbean communities. Her literature focuses on the portrait of queer subjectivities and the celebration of Afro-American identity. In this paper, I connect the different arenas in which the author corroborates her political engagement in order to propose a new perspective on autobiography as a literary genre, including such a paradigmatic platform for self-representation as Facebook. This strategy, in turn, is coherent with the author's proposal, since it is founded on the creation of a network of support for vulnerable communities and on the defense of a deep decolonization. Accordingly, the analysis and visibility of different ways to represent bodies and subjectivities converge in a study that, ultimately, questions the parameters in which writing, genre and nation are founded and interconnected.

KEYwORDs: autobiography, queer, afro identity, social media, decoloniality.

DOI: https://doi.org/10.25145/j.clepsydra.2021.21.06 


\section{INTRODUCCIÓN}

Escribe Yolanda Arroyo Pizarro en un post en Facebook con motivo del derrumbe del telescopio de Arecibo: «Somos la novela puertorriqueña del deterioro» («Somos la novela...»). Esta oración, aun con su brevedad, entraña múltiples reflexiones que pueden trasladarse al ejercicio de la escritura autobiográfica en relación con la escritura de la nación. El «somos» del inicio aparece vinculado a una concepción de la literatura con implicaciones nacionales. El yo y sus vivencias se insertan en la categorización más amplia de una colectividad a la que se le presupone un ejercicio escritural compartido. Al mismo tiempo, el deslizamiento entre un hecho real y su posible acomodo a una ficción, o a ser constitutivo de Historia, se valora en términos de frustración o de presencia de componentes que se denuestan al interior de una literatura nacional. Parte del ser constitutivo del verbo de partida se adjetiva con «deterioro», es decir, que las personas con las que se agrupa lx sujetx de escritura se identifican con lo desperfecto o lo dañado.

A partir de este estímulo me pregunto, por un lado, qué componentes o cuerpos quedan fuera en la escritura o representación del Estado nación, es decir, del lado del deterioro. Y, por otro, me interesa observar cómo se escriben las historias individuales de estos cuerpos otros, particularmente los afrodescendientes y los cuirs ${ }^{1}$ en un proyecto nacional que sólo los concibe desde su exclusión. A este respecto, Zaida Capote Cruz entiende «el espacio autobiográfico como espacio de poder» (16) y ello, en el caso de las escrituras de subjetividades y cuerpos periféricos de la representación general de una sociedad dada, encuentra un matiz extra y es que la autobiografía se convierte en acto de resistencia política y de autorreparación, al ocupar un espacio de escritura oficialmente negado. Además, esta cuestión de partida implica otras, como qué ocurre con la escritura autobiográfica en la relación con la historia de una comunidad-nación cuando las identidades corporales se ubican en el tránsito, tanto identitario como nacional. Me refiero a las identidades que no se pueden asir a una categoría consabida sino que se ubican en el intersticio, esto es, el espacio entre mundos (Anzaldúa 42).

A su vez, para abordar la autobiografía, me valdré del enfoque que están teniendo los estudios narratológicos actuales. Estos defienden la integración, siguiendo cierta inspiración etnográfica de otro tipo de herramientas útiles para la construcción de la escritura biográfica, entre las que se incluyen los blogs o las redes sociales (Calzati y Simanowski 24). Dichas plataformas expanden los horizontes hasta ahora contemplados para abordar las narrativas del yo debido a que, por un lado,

${ }^{1}$ Utilizo el término «cuir» desde lo que autorxs como Michael Warner entienden como "queer ethic». Desde este posicionamiento se expone cómo la dignidad de la homosexualidad y de los géneros disidentes se plantea desde lo vergonzoso, debido a una valoración categórica establecida desde lo «straight» o «normal». Esta última es la categoría que asume la autoridad moral, desde la que se determina que el sexo queda reservado al ámbito privado y heterosexual, con lo que todo lo que se lleve a la vida pública y fuera de esta condición de heterosexualidad obligatoria se relega al ámbito de lo avergonzante (36-37). 
no encuentran límite para albergar datos pero, por otro, se tienen que acomodar a los formatos de brevedad, listas preestablecidas o el espacio limitado para rellenar ciertos prompts (25). Asimismo, tal circunstancia determina qué información es la relevante y cuál se omite a la hora de describir un perfil de usuario (Mcneill 68-69). Suele tratarse de relatos amoldados a la inmediatez y sujetos a valoración constante por parte de seguidorxs (Calzati y Simanowski 25). Se encuentran condicionados por los algoritmos de Facebook, que crean determinadas dinámicas para recordar publicaciones anteriores o privilegiar las actualizaciones de los muros de otrxs integrantes de la red (36). Cabe recordar que los algoritmos responden a patrones que dirigen el consumo, según los intereses de socios mercantiles y patrocinadores de la red social en sí (Mcneill 78). En este sentido y atendiendo al formato virtual de partida, resulta cuestionable la lógica de la autobiografía como una narrativa puramente individual creada por un sujeto enteramente autónomo (66).

Para entrar en materia, me fijaré en la autora de la cita del inicio: Yolanda Arroyo Pizarro, una activista, escritora, académica y profesora comprometida con las comunidades vulnerables. Se instala estéticamente en la tradición de literatura caribeña que expone las complejidades de las relaciones entre islas, la heterogeneidad y el carnavalismo con que han sido abordadas (Benítez Rojo; Glissant), pero dando un paso más, al centrarse en las concretas implicaciones que la diversidad de género y la sexualidad encuentran, en intersección con la raza. Nacida en Guaynabo (Puerto Rico) en 1970, Arroyo Pizarro cuenta con una cuarentena de obras publicadas entre narrativa, poesía, antologías o narrativa infantil y juvenil. Fundó la Editorial Boreales en Puerto Rico y ha recibido varios premios por su producción literaria. Es una de las grandes exponentes de la literatura puertorriqueña y latinoamericana contemporánea en general y del colectivo cuir y afrodescendiente en particular. Como fruto de su activismo en el marco de la defensa de los derechos LGBTI y de la afrorreparación, funda en 2015 la Cátedra de Mujeres Negras Ancestrales, un proyecto de escritura colectiva de rescate de la historia de la negritud protagonizada por las mujeres o ancestras y de la puesta en valor de la afroidentidad. Como figura pública ha militado a favor de la excarcelación de presxs políticxs puertorriqueñxs y en defensa del matrimonio igualitario, como ejemplos más conocidos (Large 267). De hecho, en 2015, se casa con Zulma Oliveras Vega, convirtiéndose en la primera pareja de personas del mismo sexo que recibe la licencia matrimonial puertorriqueña. Arroyo Pizarro es una reconocida activista y promueve continuos debates y talleres para la visibilización de los conflictos generados por el racismo y el patriarcado imperantes en su Puerto Rico natal, donde reside y donde vincula la mayor parte de sus acciones.

\section{DIARIOS DE LO PERSONAL, DIARIOS DE LO POLÍTICO}

Las autobiografías contemporáneas se escriben también en las redes sociales. Ante la ausencia de espacios tradicionales en los que puedan encontrar su acomodo identidades diversas, internet se presenta como un campo amplio en el que debatirse, enunciarse y darse encuentro. Las redes sociales traducen cierta democratización en 
las prácticas de la construcción del yo y apelan a aspectos tan importantes a tener en cuenta en este ámbito como son la singularidad, la agencia y la accesibilidad (Mcneill 66). Relaciono este aspecto con algo que indica Capote Cruz sobre las autobiografías convencionales: "Al construir su propia imagen en el texto, el autobiógrafo está recuperando la posibilidad de autocomplacencia» (29) que, añado para el caso de las sexualidades disidentes, raramente puede proceder de un elemento externo ya que, como identidad excluida, nunca va a encontrar un espacio de representación que asuma sus especificidades, de ahí que la subjetividad no representada cree sus propios mecanismos de complacencia.

Traigo a colación de nuevo las palabras de Capote Cruz, cuando señala que «El discurso autobiográfico femenino que desoye los mandatos de la tradición, evidentemente patriarcal, estará asumiendo una actitud subversiva frente a la ideología en la que esa tradición se sustenta» (26). En gran medida, la acción de la escritura aquí se encontraría inserta en la famosa cuestión lanzada por Gayatri Chakravorty Spivak de si el subalterno puede, efectiva y totalmente, acceder al habla o a formular un discurso propio si el sistema desde el que lo articula está sumido en una lógica, explicada por Antonio Gramsci, de preeminencia de lo hegemónico frente a lo subalterno (Spivak 321).

Enlazando estas ideas con las mentadas posibilidades de la cibernética, Eduard Arriaga Arango indica que Arroyo Pizarro ejerce un cimarronaje electrónico (Arriaga Arango 31). Con ello se refiere a que la escritora y activista se vale especialmente de su blog narrativadeyolanda.blogspot.com y de las cuentas de Facebook que administra no sólo para difundir su obra escrita, sino como espacio de denuncia de las comunidades vulnerables. Una de las expresiones literarias de esta vocación activista se expresa en el poema de la autora publicado repetidas veces en Facebook «Yo, Makandal», incluido en un poemario que porta el mismo título. En él se rememora la figura histórica de uno de los cimarrones más conocidos del siglo XVIII en la colonia francesa de La Española afirmando con rotundidad: «Seré Makandal / guerrera transmutada en el género que sea necesario / para destronar este racismo" (Arroyo Pizarro, «Seré Makandal...»). Se trata de una relectura mítica que incluye el cuestionamiento de género, además de posicionarse desde la mutabilidad y no estatismo de este. «Seré Makandal / y mi dominio será esta patria de discrimen y desigualdad / que convertiré en antirracista, en abolicionista", "porque se nos va la vida / a mí, a mis hermanos de lucha, a nuestros hijos y nietos por venir» (Arroyo Pizarro, «Seré Makandal...»). Relaciono el poema con algo que escribe Raúl Guadalupe de Jesús, cuando observa la importancia del referente histórico de Makandal en relación con el Caribe contemporáneo: «De esa manera la mano de Makandal podrá seguir excavando las profundidades del Caribe, ya no en el reino de este mundo sino más bien en el reino de todavía» (82).

La cita hace referencia a la novela de Alejo Carpentier titulada El reino de este mundo (1949). Esta obra literaria constituye uno de los referentes más importantes de lo que el propio autor cubano denomina «lo real maravilloso» y se centra en la Revolución haitiana iniciada en 1791, cuyos actores se inspiraron en la figura de Makandal, que había sido ejecutado décadas antes por apalencamiento. En la ficción de Carpentier quedan retratadas ciertas ambivalencias al sentido de la tem- 
poralidad a las que apela tanto la cita destacada como el poema de Yolanda Arroyo Pizarro. Siguiendo a Glodel Mezilas, me refiero al tiempo sagrado vudú versus tiempo profano de la esclavitud colonial, en conexión con el valor verídico y actual que alcanza en el contexto caribeño de hoy la figura del cimarrón. Aplicando las palabras de Mezilas, la activista puertorriqueńa sería una cimarrona que acciona la memoria y apela al imaginario "como mecanismo de la acción colectiva» (Mezilas 85). Además, los ritos de Makandal no sólo activan la memoria solapada por el orden colonial y racista, sino que también funcionan como mecanismo de cohesión y de empoderamiento de las comunidades afrodescendientes (ibid.). En este sentido, la práctica ritual fue «una fuerza vital que animó a los esclavos a luchar sin parar contra las injusticias y las violencias coloniales» (Mezilas 92). De la misma manera, la invocación de Arroyo Pizarro en su poema es de tal relevancia que trasciende al tiempo y a la represión sufrida, es decir, se colocaría en lo que Mezilas denomina «tiempo sagrado». Se refiere a la temporalidad a la que no tenían acceso los amos, concentrada en el tiempo del ser, el tiempo de comunión con los dioses o el «de reapropiación del pasado» que se oponía al tiempo del no ser, es decir, el profano o del ser únicamente como esclavo (101). Así, el poema actualiza el poder de subvertir los órdenes impuestos, para procurar la liberación negra en contexto colonial, paralela a lo que constituye la liberación del territorio puertorriqueńo del racismo y la violencia, así como la liberación de los cuerpos encerrados en el binario de género de orden patriarcal.

El poder del rito en la autora boricua se materializa recurrentemente a través de acciones de vocación colectiva, las cuales considero expresiones contemporáneas de cimarronaje. De hecho, la alusión a Makandal aparece de nuevo y repetidamente a partir del 12 de octubre de 2020 en su muro de Facebook. Ese día coorganiza y participa de un rito en forma de ofrenda floral, canto y baile titulado "Junto a la mar, vivas y en resistencia». Para contrarrestar la conmemoración del inicio del genocidio americano, esta acción plural, convocada, entre otras, por la Cátedra de Mujeres Negras Ancestrales, que dirige la propia Arroyo Pizarro, celebrada en la playa de Piñones, en Puerto Rico, se suma a la Acción Global por la Anulación de la Deuda y al Día de Resistencia Indígena y Negra. La ofrenda floral se dedicaba a las deidades afrocaribeñas del mar y entre las reivindicaciones se concentraban la afrorreparación, la resistencia, el antipatriarcado, la defensa del Black Lives Matter, la solidaridad con el pueblo haitiano, la memoria vulnerada o la revisión del régimen del libre asociacionismo de Puerto Rico. Entre otras actividades propuestas, se llevó a cabo un taller de escritura creativa colectiva a través del ejercicio de «La cuerpa exquisita» en lugar del conocido ejercicio surrealista del "cadáver exquisito» y se celebraron rituales de empoderamiento femenino como el yoga ( 12 de octubre»). La convocatoria, recogida a través de varios post con videos, fotos y mensajes en Facebook, se inscribe en la urgencia por encontrar espacios descolonizados en el que las identidades excluidas de la palestra pública puedan desarrollarse y encontrar su acomodo. Con la actividad, las personas congregadas participan de la tradición invisibilizada de la afrorresistencia, defienden la sororidad, además de proponer y ejecutar una serie de proclamas relacionadas con la denuncia de la violencia racista y machista. Con su difusión por redes sociales se contribuye a su visibilización y 
a la creación de un archivo accesible a lxs usuarixs. Así, la escritura de las propias vivencias de un 12 de octubre descolonizado a través del rito contribuye al cuestionamiento de la conmemoración del genocidio caribeño y americano y, con ello, a debatir el sentido de la nación puertorriqueña contemporánea, asentada en la tradición colonial iniciada en dicha fecha.

Internet y activismo se imbrican constantemente en el caso de Arroyo Pizarro. Ambas vías, unidas a la creación literaria, vehiculan las demandas y reivindicaciones de las que la autora se hace eco. En este sentido, la escritora boricua considera todos los ámbitos de la vida en los que ejercer una descolonización profunda y transversal, como la autorrepresentación, la nación o el amor, siendo el cibernético un espacio más de entre tantos a descolonizar ${ }^{2}$. Este, además, se encuentra revestido de una importancia fundamental dado que constituye, a su vez, una red de difusión de gran potencial. Al mismo tiempo, se erige como un medio exitoso de conexión y comunicación entre identidades subalternas, ya que democratiza las opciones de representación. Arriaga Arango denomina a esta estrategia y efecto en el uso de las redes como una construcción de «una poética electrónica de los desprotegidos» (27). Aprovecho un post publicado en el Facebook de la autora como ejemplo para explicar la idea:

Los hombres caciques de los grupos indigenistas en $\mathrm{PR}^{3}$ me acusan de «faltar el respeto a la vida" porque creo en el aborto y en la sexodisidencia y diversidad indigenista. Los hombres de grupos antirracistas y que defienden la negritud me acusan de degenerada porque soy lesbiana y apoyo a la hermandad Trans. Los hombres escritores babalawos ${ }^{4}$ blancos me hacen whitesplaining ${ }^{5}$ y me acusan de no defender la negritud como la defienden ellos. Los hombres negros escritores antirracistas me acusan de escribir únicamente de mujeres negras ancestrales y no de hombres. ¿Cuál es el factor común? Cuando sumen, resten, multipliquen y dividan, calculen la respuesta. Descubrirán a todos Los Tóxicos que tenemos en nuestros espacios de resistencia como falsos aliados («Los hombre caciques...»).

2 Con «descolonizar» me refiero a emprender acciones o críticas que contrarresten las consecuencias de lo que se denomina colonialidad. Con este apelativo se denomina la impronta que ejercen en el presente las relaciones de poder instauradas entre las subjetividades que experimentaron o participaron de la colonización europea (Quijano 285-286). La colonialidad ejerce un impacto en todas las esferas que atañen a las personas que la viven, creando determinadas problemáticas en torno a la raza, el género, la sexualidad, la corporalidad, la espiritualidad, el territorio o el lenguaje, entre otros ámbitos. Así, lo descolonial es una perspectiva epistémica que comprende la continuidad entre las desigualdades sociales, culturales o económicas que se producen al interior del capitalismo global contemporáneo y la colonización moderna (Castro-Gómez y Grosfoguel 14). Procede de una tradición de pensamiento que arranca con las perspectivas poscoloniales de mayor anclaje en el ámbito anglosajón -aunque no exclusivamente-, para luego encontrar una concreta aplicación en Latinoamérica, a través del grupo colonialidad/modernidad (Castro-Gómez y Grosfoguel 9-13).

3 Abreviatura de Puerto Rico.

4 Tipo de sacerdote de la religión yoruba.

5 Explicación condescendiente que ejercen las personas blancas a las que no lo son. El whitesplaining, como manifestación de superioridad de conocimiento, de poder y de capacidad expresiva, es síntoma de colonialidad aplicada a la categoría de raza. 
A través de una denuncia enfocada en los particulares ataques o críticas que recibe la escritora, expone sus compromisos con diferentes grupos disidentes y excluidos de la voz pública, como los sexodiversos, los afrodescendientes o los revisionistas de la historia blanca y patriarcal. Con esta entrada a su diario personal, traslada un conjunto de problemáticas de fuerte cariz político. Al mismo tiempo, alude a la complejidad de las relaciones de poder que se generan también al interior de colectivos excluidos de privilegios, reproduciéndose jerarquías por razón de género o sexualidad que trasladan parejos signos de opresión denunciados desde, en este caso, subjetividades marginadas por motivo racial y/o étnico. Se desprende la conciencia de la interseccionalidad en la escritura y en el retrato de la realidad, que lleva a una determinada comprensión de las relaciones de poder y de las desigualdades, generando intersecciones que confluyen tanto en los diferentes tejidos sociales como en las experiencias individuales vividas en la cotidianeidad (Hill Collins y Bilge 2). Esta definición más o menos extendida de la interseccionalidad entronca con el sentido del diario personal / diario político con el que abordo la escritura del yo en Arroyo Pizarro. La autora y activista ejemplifica cómo la subalternidad no se presenta como una condición homogénea o que responda a un único indicador, sino que es consecuencia de un sistema complejo en el que las diferentes categorías implicadas no se comprenden desde su oposición sino desde la interconexión (Hill Collins y Bilge 33). En el caso de la escritora boricua, el género, la sexualidad, la raza, la etnia, la condición colonial y la clase social engrosan el entramado de categorías interconectadas. El compromiso de la autora es abarcador y pretende integrar a aquellas comunidades marginadas de la escritura oficial, tanto del pasado como del presente, considerando «internet como una red que en sí misma le permite la articulación compleja de la diferencia» (Arriaga Arango 30). De manera que, a un cimarronaje contemporáneo ejercido como posicionamiento político y vital, ligado fuertemente a la tradición de resistencia colonial caribeña, se le complementa un cimarronaje electrónico.

El terreno epistémico y vivencial en el que se ubican la crítica al heteropatriarcado y la defensa de la diversidad sexual de Arroyo Pizarro se adscribe expresamente al Caribe. Este anclaje no sólo se evidencia a través del importante factor del cimarronaje, que retrotrae a un contexto histórico colonial preciso, sino también al de adscripción al de una tradición crítica, que arranca con los primeros movimientos latinoamericanos de sexualidades disidentes de finales de los 60, protagonizados por varones homosexuales. Las lesbianas, como categoría en sí misma, comenzaron a asomar en la década de los 80, en el marco de los Encuentros Feministas de América Latina y el Caribe (Espinosa Mińoso, «Historizar las disputas» 244), y, para el caso concreto de Puerto Rico, de la mano de las primeras publicaciones de las poetas Nemir Matos-Cintrón y Luz María Umpierre (Aponte Parés et al. 6; Lladó Ortega 273). Así, ante la inicial invisibilidad del lesbianismo, este comenzó a articular discursos alternativos que no condenaban únicamente la homofobia, sino también el sexismo o el racismo (Aponte Parés et al. 6). Se insertaba, en cierta manera, en la tónica de la interseccionalidad que encontró un productivo terreno de aplicación en los feminismos poscoloniales. La metodología que proponen parte de la consideración de los vínculos que existen entre género, raza, 
sexualidad y clase a la hora de explicar las violencias infligidas sobre las mujeres no blancas (Lugones, "Colonialidad y género" 76). En la década siguiente, surgieron grupos lésbicos que se escindieron del feminismo para encontrarse más en consonancia con los movimientos LGBTI, centrando su crítica en el «régimen de la heterosexualidad obligatoria» (Espinosa Miñoso, «Historizar las disputas» 246). Arroyo Pizarro se coloca en esta tendencia de escritorxs boricuas iniciada en los 90, como la de Negrón-Muntaner, Luis Aponte-Pares o Lawrence La Fountain-Stokes, de documentar las historias LGBTI en Puerto Rico (Aponte Parés et al. 7), además de apoyar el posicionamiento cuir como modo particular de abordar las nociones de soberanía y nación específicas de la isla boricua (Aponte Parés et al. 8). El activismo puertorriqueño LGBTI actual reconoce los cambios producidos en los últimos cincuenta años, sin embargo, el relativo progreso sigue condicionado por el estigma de la exclusión y por los nuevos retos que aparecen en su intersección con el feminismo, el medioambientalismo, la descolonialidad, la salud, el matrimonio igualitario, el cambio administrativo del nombre para personas transgénero o la violencia doméstica en parejas homosexuales, entre otros aspectos (La Fountain-Stokes y Martínez-San Miguel 7). Junto a importantes personalidades de la literatura y el compromiso afrofeminista y/o cuir puertorriqueño como Mayra Santos-Febres e Yvonne Dennis, Yolanda Arroyo Pizarro se convierte en una de las activistas LGBTI más conocidas de su país debido a su tenaz labor en el ámbito comunitario, académico y, también, el digital.

De manera que, a la hora de abordar el Facebook de Arroyo Pizarro como un diario personal, cabe enfrentar la cuestión de la verosimilitud en la escritura, así como las fronteras entre ficción y realidad. Capote Cruz entiende que «La autobiografía ha sido tradicionalmente percibida [...] como un discurso sumamente subjetivo, más cerca de la ficción que de la historia» (17). Sin embargo, al tratarse de obras que son concebidas para retratar la realidad de lx autorx, se convierten en textos con fuertes implicaciones históricas, de manera que actúan como referentes u obras de consulta a la hora de interesarse por una determinada realidad social o cultural. El uso de las redes sociales como forma contemporánea de autobiografía responde al mismo funcionamiento. De hecho, la necesidad real de interconexión entre subjetividades se traduce, entre otros aspectos, en la popularidad que alcanzan estas plataformas, acelerando la creación de redes de conexión entre familias, gremios, amistades y demás grupos con intereses compartidos (Mcneill 66). Para lx autorx sirve como forma de autorrepresentación ante la carencia de otros espacios y para $\mathrm{lx}$ lectorx como texto de referencia, cuando trata de acercarse a una realidad. Un diario cibernético en forma de blog o de perfiles de Facebook, Instagram, Snapchat o Twitter amplía con creces los contenidos que engrosan las obras históricas tradicionales, de manera que se convierte en una fuente de consulta que ensancha las posibilidades incluyendo, en muchas ocasiones, a actorxs no consideradxs en la historia oficial. Cabe aclarar que, como fuente de referencia, no está exenta de someterse a juicios sobre su grado de verosimilitud, es decir, como indica Foucault a propósito de proceder a la arqueología del saber, que se valore si la información que porta es sincera o falsa, si está contrastada o es de naturaleza aleatoria, si es auténtica o se encuentra alterada (L'archéologie du savoir 13). En este sentido, la relación entre 
autobiografía y Facebook vuelve a incidir en la cuestión de la autenticidad y quiénes son los sujetos encargados de validarla (Mcneill 68).

\section{AUTOESCRITURA, AUTORREPARACIÓN}

Ochy Curiel, en su análisis de lo que denomina «nación heterosexual», entiende «la ley y la escritura como medios y tecnologías de establecimiento del poder y la hegemonía» (27). Ahora bien, el acceso a la escritura en general y a la redacción legislativa en particular en sociedades heteropatriarcales y coloniales se revela desigual. La antropóloga dominicana demuestra, tomando el ejemplo de la Constitución colombiana de 1991, cómo «el régimen heterosexual está relacionado con la nación» (Curiel 26), generando un entramado de exclusiones de mayor incidencia sobre las mujeres y, más aún, sobre las lesbianas. La homosexualidad femenina rompe la tónica, facilitada por los aparatos del Estado, de que la masculinidad normativa acceda física, económica y emocionalmente a las mujeres (Curiel 30). Ante tamaño panorama, la llegada a la escritura de identidades sexuales disidentes supone todo un acto de resistencia.

Previamente, Frantz Fanon sienta el primer gran precedente articulado de las relaciones entre raza, colonialidad y lenguaje cuando aborda las vicisitudes que enfrentan lxs negrxs antillesxs en sus relaciones con la metrópoli. Indica que toda sociedad colonizada tiene que lidiar con la lengua del pueblo colonizador (Fanon, Peau noire 14). La comunidad afrodescendiente, en este contexto, experimenta un dispar acceso a la lengua y, por tanto, a la escritura. Por otro lado, el autor martiniqués iguala colonialismo a violencia (Fanon, Les damnés 61). Añade que el maniqueo orden que se genera como consecuencia entre opresorxs y oprimidxs, así como la violencia estructural, se conservaron intactos durante el periodo de descolonización (52) y durante la posterior "vie nationale» (75). Sin que Puerto Rico haya experimentado una descolonización propiamente dicha, en la redirección del colonialismo español al estadounidense (García Muñiz 537-538; Malavet) pervive el maniqueísmo colonial.

Desde la conciencia de la continuidad de la violencia hacia los sectores dominados por la maquinaria colonial que destaca Fanon, así como de la heteropatriarcalidad inherente al contrato nacional tal cual lo defiende Curiel, Arroyo Pizarro explora las vertientes derivadas de los dos aspectos aplicadas a la sexualidad y a la raza en relación con la escritura. La autora detecta las áreas en las que la colonialidad ejerce su impronta y reflexiona sobre maneras de descolonizar los cuerpos y subjetividades a las que impacta. De manera que la violencia sufrida sobre el cuerpo propio se desarticula a través de, por un lado, la escritura que ayuda a subvertir el sentido anulatorio de la agresión con la autorreparación y, por otro, de compartir la experiencia propia como motivo de encuentro entre otros cuerpos violentados. La importancia de las ancestras aquí subraya el efecto plural de la reparación, ya que su figura reúne la importancia de la memoria no relatada debido a la invisibilidad conferida a las mujeres negras en los relatos del pasado y, simultáneamente, se reivindica la filiación o deuda espiritual que se les confiere. 
A través de este y otros referentes se alimenta el sentido político de la acción de la escritura, a la vez que se crea comunidad, unida por la empatía de haber experimentado una violencia de similar origen.

Arroyo Pizarro, en su novela titulada Violeta, muestra al personaje de Vita Santiago, quien sufre continuas violaciones de su padre durante la adolescencia. La Diana niña del relato titulado "Después de martillar» (Arroyo Pizarro, Lesbianas en clave caribeña 13-15) padece lo mismo pero siendo su padrastro el violador. Ricardo Santos, en «Los niños morados» (Arroyo Pizarro, Transcaribeñx 57-73), es agredido continuamente por los niños de su colegio por no cumplir con una masculinidad normativa. Se trata de los mismos niños que obligan a Ricardo a que les haga felaciones a escondidas. En dicho relato, su protagonista recibe amenazas por ser «mujer y machúa» (59). En otro, titulado "Hijos de la tormenta» (Arroyo Pizarro, Transcaribeñx 75-94), Roberto se suicida disparándose al ver fracasada su heteronormatividad cuando se entera de que se había enamorado de un güevedoce ${ }^{6}$. Como ejemplo verídico de las consecuencias de los tabúes en torno a la sexualidad, la propia Arroyo Pizarro indica en su diario virtual que la pérdida de la virginidad con su novio de entonces no fue un momento placentero, debido al desconocimiento que tenían ambxs ya que el tema no se trataba en su complejidad en sus respectivos entornos ("Camino al campo de Caguas...»). Ante este hecho, la escritora propone romper este pacto de silencio e invita a sus seguidorxs a valorar si sus primeras experiencias sexuales fueron placenteras o no. La ruptura del silencio pactado que mantiene el statu quo constituye uno de los elementos claves para poder escribir el cuerpo y, por tanto, colaborar en que las identidades disidentes encuentren otra forma de existir en una nación que no sea desde su exclusión. Michael Foucault explicaba que el sexo y la sexualidad se convierten en elementos secretos, silenciados e invisibilizados de la sociedad victoriana, en favor de la reproducción como supremo valor familiar y social (Histoire de la sexualité 10). La represión en torno a la sexualidad crea una serie de tensiones de poder de quien articula la palabra y quien define la sexualidad (28-30) e, incluso, llega a vincular la estabilidad de una sociedad a la sexualidad de sus integrantes (37). Así, el sexo pasa a ser controlado por el Estado y sus poderes fácticos. Lo que exceda a lo prescrito por él, entonces, será objeto de represión. Como consecuencia, la sexualidad permitida es la heterosexual, monogámica y patriarcal que concibe a la mujer como útil desde su rol reproductivo. Lo otro existe sólo desde los márgenes del relato de la nación y, por tanto, se encuentra sujeto a juicio y persecución constante.

Arroyo Pizarro denuncia el 13 de agosto de 2020 en su cuenta de Facebook la violación en manada de una mujer en el municipio puertorriqueño de Ańasco producida unos días antes, alertando de que «Nuestro país es un gran cómplice de la violación sexual» («Nuestro país...») al evidenciarse la desprotección de la víctima

${ }^{6}$ En República Dominicana, esta denominación se refiere a lxs niñxs intersexuales que nacen con genitales femeninos, pero que en torno a los 12 años viven una transformación hacia el desarrollo de órganos sexuales masculinos. 
no sólo por los horribles hechos sufridos sino por la impunidad con que se afrontan desde los estamentos judiciales y la opinión pública, que colocaba a la víctima en el centro de la culpabilidad. Este reforzamiento machista entre estamentos de poder, que perpetúa la excepcionalidad jurídica que experimentan los cuerpos excluidos de la nación, lleva a la escritora a aseverar: «Este país violó a esa muchacha» («Nuestro país...»). Se observa aquí, de nuevo, el recurso de la escritora en contextualizar los hechos violentos que sufren las personas y el concreto marco nacional en el que se inscriben.

Elena Valdez destaca en su artículo la denuncia pública que Arroyo Pizarro emprendió contra otro pacto de silencio: el de la pedofilia y el abuso infantil en Puerto Rico a través de, entre otras herramientas, un post de Facebook en marzo de 2017. Valdez entiende, en una reflexión que extiendo a la más reciente violación grupal de Ańasco, que tanto la novela Violeta como las publicaciones en Facebook se convierten en medios de denuncia de «la violencia inherente en el heteropatriarcado y [...] [que buscan] romper con la sociedad que encubre a los infractores como los bastiones del núcleo heteropatriarcal diseñado para reproducir lo normativo" (300). Violeta sería un texto ficcional que, entre otros aspectos, coloca como atroz raíz de los problemas de salud mental que padece Vita Santiago las violaciones que sufría por parte de su padre con la connivencia del silencio de su tía Violeta. El segundo sería un texto integrante del muro de Facebook de la autora, que funciona como diario público, en el que manifiesta su repudio hacia el abuso infantil al mismo tiempo que expone el funcionamiento y la red de complicidad desplegada para silenciar los casos cotidianos.

Desde esta perspectiva política, Arroyo Pizarro utiliza el principio de funcionamiento de Facebook de alimentarse de la producción continua de narrativas que se relacionan entre sí, en una simbiosis constante de construcción autobiográfica propia y de lxs demás (Mcneill 71) para conectar una serie de hechos reales e integrarlos a una red de denuncias. Así, las noticias, los testimonios ajenos y propios, las actividades en colectivos, los registros audiovisuales, las citas a textos propios y ajenos, la publicación de poemas o relatos cortos, las campañas y challenges como \#EnnegrecetuProntuario, del que hablaré más adelante, que integran el diario cibernético Arroyo Pizarro suponen una apropiación de los espacios que generan las redes. Entre otros aspectos, sirven para denunciar los abusos de un sistema patriarcal y racista, por lo que el uso de la red denota lecturas complejas y profundas.

A su vez, en el retrato del yo generado a partir de Facebook se combina la escritura y la imagen. Luz Marilyn Martín Sánchez indica que a pesar de la acorporalidad con la que se plantea la comunicación por chat, «Internet está lleno de cuerpos que interactúan en [...] [lo que se] denomina "tecnopresencia"» (305). En el caso del concreto uso que hace Arroyo Pizarro, una descripción verbal en el muro puede venir acompañada o no por el apoyo audiovisual, o bien la publicación de un video o de una foto puede aparecer sin ningún tipo de información escrita. Las posibilidades del diario virtual incluyen, entre otras opciones, determinar la ubicación en la que se produce el estado o si lx usuarix se encuentra acompańadx por otras personas. La autora asienta parte de su actividad en el poder de la imagen a la hora de abordar la afroidentidad. La reparación pretendida es transversal a todos 
los órdenes y, atendiendo a la importancia de lo audiovisual en el momento actual, busca nutrir la representatividad de corporalidades negras y no normativas en los medios. Su ejercicio es retroactivo, de manera que no sólo se apoya en los hechos del presente, sino que busca rescatar del olvido y la exclusión a personas que han contribuido al antirracismo. Así, la relación entre escritura e imagen se encuentra estrechamente vinculada con la memoria y la creación de archivo. En este sentido, Leonor Arfuch desarrolla todos los desencadenantes de dicha simbiosis:

... la relación intrínseca entre memoria e imagen, la carga afectiva y el impacto corporal que esto supone, su cualidad de acontecimiento, en tanto transformación del estado de las cosas y puesta en juego de la temporalidad, la paradójica tensión entre presencia y ausencia, lo irreductible de la experiencia personal que sin embargo nunca deja de ser colectiva (401).

A la luz de la cita, se redimensiona el sentido de las fotos de juventud que en ocasiones postea Arroyo Pizarro, o que la escritora boricua se esfuerce en reunir en su cuenta de Facebook pruebas fotográficas y audiovisuales de las acciones cotidianas que contribuyen a los objetivos políticos expresados. A su vez, alimenta la idea de comunidad y de relación que subyace en el universo creativo de Arroyo Pizarro, desplegada en múltiples frentes, como son la creación de materiales de lectura para público infantil afrodescendiente o la difusión de conocimiento afrocentrado a través de su editorial. Las posibilidades del diario virtual se encuentran fructíferamente con el sentido interseccional de las reivindicaciones de la autora, forjando un perfil muy activo en las redes que se nutre tanto de sus propias intervenciones como de las que comparte de otras páginas y de las de sus seguidorxs.

Laurie McNeill subraya cómo las redes sociales acentúan el carácter colectivo de las subjetividades, evidenciando el obligatorio sentido de relación que se encuentra al interior de toda narrativa autobiográfica ya que, explicado sucintamente, las historias personales interactúan constantemente con las historias personales de otrxs (73). Al mismo tiempo, se propone con ello un modelo de autobiografía inusitado por cuanto necesita continuamente de historias «nuevas», de comentarios de lectorxs que pasan, con ello, a contar con cierta agencia autoral. Se relativiza el sentido del yo liberal que se construye a sí mismx, pues en este escenario se precisa de la actuación expresa de lxs otrxs integradorxs de la red (74). Esto genera múltiples implicaciones que se convierten, en el caso de Arroyo Pizarro, en los puntos fuertes de su escritura.

Además, los elementos autobiográficos presentes en el muro de la autora son integrantes válidos a archivar. Apelo aquí al sentido del archivo explicado por Yuderkis Espinosa Miñoso como conjunto de testimonios, experiencias y documentos que contribuyen a emprender una genealogía de lo que ella denomina como «la razón feminista en América Latina». Esta, embebida de los presupuestos de los feminismos negros y de color, busca criticar «los métodos de producción de conocimiento por parte de la ciencia moderna [...] [proponiendo] en su lugar el uso de la experiencia como forma efectiva de construcción de saber ("Hacer genealogía de la experiencia» 2018). La alta actividad de Arroyo Pizarro en todas las escenas destacadas traslada el ímpetu por engrosar los archivos ausentes. Me refiero con ellos a los de las histo- 
rias que transitaron subterráneamente a la Historia objetiva, blanca y cisgénero, que están en proceso de valoración y de acopio a través de acciones y posicionamientos tan necesarios como el que ocupa a la protagonista de este trabajo.

\section{HISTORIAS INDIVIDUALES, HISTORIAS NACIONALES}

La historia individual y la historia nacional se cruzan en el caso de las comunidades invisibilizadas de los discursos hegemónicos que deciden reescribir su historia y la Historia desde parámetros otros. En el caso de la obra literaria de Arroyo Pizarro, Sophie Large subraya su recurrencia de la narración autodiegética y el efecto que ello genera (Large 263). Esta preferencia traslada la intención de la autora de retratar en su profundidad y complejidad las subjetividades cuirs (ibid.). Dicha elección diegética contiene también un posicionamiento político "ya que la ductilidad de su mensaje reside precisamente en la abundancia de signos y en el desplazamiento constante de las conexiones que obligan a considerar sus textos literarios no como obras independientes y autónomas sino en sus relaciones entre sí» (Large 265). A la relación destacada entre obras literarias, añado los textos y escrituras autobiográficas trasladadas desde el Facebook de la autora y su blog. De manera que se difuminan las fronteras entre ficción y realidad personal-nacional.

Centrándome en el motivo del activismo desde la ficción, en las obras narrativas de la escritora boricua proliferan las menciones a personalidades relevantes en la historia de la liberación de Puerto Rico, como señala Elena Valdez en su lectura de la novela titulada Violeta, «inspirada por los cambios legislativos sobre los derechos LGBT» (Valdez 297). En el relato "Hijos de la tormenta» (Arroyo Pizarro, Transcaribeñx 75-94) encuentro un ejemplo diegético de imbricación de historia individual e historia nacional. El quinto pasaje del relato narra una parte de las biografías de las madres de la protagonista contando como eje una cronología que comienza con la irrupción de cuatro nacionalistas puertorriqueńxs lideradxs por Lolita Lebrón al Congreso de los Estados Unidos en 1954, reclamando la independencia del país boricua. El vínculo con la historia política no es caprichoso, ya que el enamoramiento de las dos madres de la protagonista se produce en una de las manifestaciones por la excarcelación del grupo de asaltantes al Congreso. Isabel y Alfonsina, las progenitoras en cuestión, participan de una organización pro derechos humanos que recorre Puerto Rico para denunciar las atrocidades del imperialismo en la isla, al mismo tiempo que se convierten en ejemplo de pareja públicamente lesbiana que desea tener un hijo, para lo que acuden a un hombre dominicano, que encuentran en el peregrinaje de pueblo en pueblo, el cual acepta cederles su esperma. Así, la reivindicación evidenciada aquí es de la relación indisoluble entre sexualidad y Estado, al mismo tiempo que se observa cómo la liberación de una está relacionada con la liberación del otro. $\mathrm{O}$ cómo la escritura del yo encuentra un vínculo con la escritura de la nación de pertenencia:

Lolita Lebrón es liberada el 29 octubre de 1970, mismo día que comienzan las contracciones de mamita Isabel. A la heroína Lebrón la liberan junto a sus compa- 
ñeros en la lucha, gracias a un indulto que concede el presidente Richard Nixon. Cuentan que, debido al júbilo existente y la emoción que experimentaba el país entero ante tales noticias, a Isabel se le adelanta la labor de parto. Llego al mundo durante esa tarde de la liberación de quien luego se convertiría en nuestra gobernadora (Arroyo Pizarro, Transcaribeñx 84-85).

La elección por vincular la historia previa al nacimiento del protagonista y narrador a uno de los acontecimientos pro independencia de Puerto Rico más importantes subraya las sinergias ineludibles entre historia individual e historia nacional. Lo que sucede con posterioridad cronológica en el relato encuentra también referentes políticos para narrarse: la elección de Lolita Lebrón como gobernadora de la isla en 1975 y su reelección en 1979. Después de este hecho, se celebra el décimo segundo cumpleaños del narrador y se revela a lx lectorx su condición de güevedoce.

Aparecen más ejemplos de vinculación de historia nacional e historia individual en las ficciones de Arroyo Pizarro. Violeta cuenta con varias menciones a la encarcelación y demanda de liberación del preso político boricua Oscar López Rivera. La escritora fue una ferviente defensora de uno de los líderes del grupo que perseguía la independencia de Puerto Rico FALN (Fuerzas Armadas de Liberación Nacional), como lo demuestran las campañas que protagonizó a favor del indulto del prisionero. En la novela, el personaje de Iolante relata cómo conoció a Yuisa, una activista con la que convive desde hace años, «en una propuesta multitudinaria que exigía la excarcelación del preso político puertorriqueño Oscar López Rivera» (Arroyo Pizarro, Violeta 84). Luego de eso, tras una escapada con Vita Santiago en la que deciden despedirse tras reconocer que llevan toda la vida amándose desde la dificultad, la protagonista encuentra su refugio en otra manifestación por la liberación de López Rivera y en los brazos de Yuisa, que participaba en la protesta. A este respecto, Elena Valdez emprende una lectura de Violeta desde la relación entre la norma erótica y la norma política:

Violeta [...] cuestiona la díada monógama como la única forma legítima, natural y deseable de relaciones, que está diseñada para producir un sujeto sexual normativo, o un ciudadano homonacional, parafraseando a Jabiar Puar [...]. Por esto, en la novela, las relaciones diádicas que padecen tendencias hetero u homonormativas tóxicas dejan de ser un modelo para la nación (298).

La solución propuesta por la novela, en un final coronado por la liberación de López Rivera, es el reconocimiento de las huellas del pasado en el presente, de los daños autocausados y creados hacia las otras, así como el desengaño del amor romántico homonormativo. Retomando el análisis de Valdez, triunfa la sexualidad poliqueer como atentado contra el modelo de ciudadano homonacional, al promover "relaciones horizontales no jerárquicas», que implican «un sentido de pertenencia queer entre los personajes que profesan el amor decolonial» (298). Esta ruptura con los cimientos en los que se asientan las relaciones interpersonales en sentido afectivo y político evidencia la delgada línea que separa al cuerpo de la nación. Arroyo Pizarro incide aquí en lo transversal que resulta la descolonización del amor como medio o acción paralela a la descolonización del territorio pues, al fin y al cabo, 
se descoloniza la relación del yo con lx otrx, en su vertiente personal o colectiva. Con ello, me sumo a la interpretación de que Arroyo Pizarro está cuestionando los cimientos mismos en los que se funda el estatus neocolonial puertorriqueño, al conciliar las reivindicaciones por la diversidad sexual con aquellas proindependencia. De hecho, Diego Facolní Trávez comienza su artículo en el que vincula la obra de la escritora boricua con la de Audre Lorde enunciando que "La escritura de la narradora Yolanda Arroyo Pizarro [...] es una invitación a repensar, de diversas formas, al Puerto Rico contemporáneo» (Falconí Trávez 56). La afirmación reincide en aspectos tratados por Efraín Barradas y por Radost Rangelova en sendas lecturas de la novela de Mayra Santos-Febres, Sirena Selena vestida de pena, en cuanto a la noción de nación que plantea. La novela de Santos-Febres se centra en la temática trans y de representación de la realidad contemporánea caribeña y, por lo expuesto, puede entenderse como influyente en los presupuestos estéticos y políticos de Yolanda Arroyo Pizarro. Rangelova entiende que al presentar personas trans que migran entre República Dominicana y Puerto Rico la novela redunda en el debate del género y la nacionalidad como algo fluido y no estático (76). Ambos aspectos, además, se encuentran resignificados por el funcionamiento neoliberal, de manera que el autor apela a los lazos que se crean no tanto por una concepción nacional romántica sino por los movimientos del capital y la riqueza, que determinan la direccionalidad de la migración en el Caribe (83). El autor del artículo subraya, en una escena reveladora en el relato de Santos-Febres, una cuestión trascendental en las relaciones entre género y nación, y es que el personaje boricua de Martha Divine nunca se sintió tan asustada como cuando llegó a la aduana dominicana pues, en ese espacio, iba a ser agresivamente cuestionada y vulnerada por su subjetividad travestida (Rangelova 84).

Efraín Barradas desarrolla la idea expresada por la propia Mayra Santos-Febres de que el travestismo que retrata la novela le sirve para entender el Caribe contemporáneo y, en general, los países del llamado Tercer Mundo (Barradas 58). El turismo, según Barradas, constituye uno de los motivos capitales de esta identidad posmoderna o fluida caribeńa. La obligatoriedad de sujetarse a gustos y placeres del turista genera unas relaciones complejas de la población caribeña con su propio territorio y con el consumo turístico que llega, convirtiéndose las islas en especies de parques temáticos que concentran una serie de prestaciones sexuales, de consumo, de placer, en omisión de otros elementos que también componen la realidad, «Dentro de ese marco, entonces, los travestis de la novela se convierten en representaciones de esa historia, de la historia del Caribe que usualmente se ignora» (59).

El relato "Changó» (Arroyo Pizarro, Transcaribeñx 15-26) aborda las identidades nacionales y de género fronterizas. En la narración, Arroyo Pizarro retrata a un dominicano llamado Changó Almonte, que llega en yola a Puerto Rico. Se trata de un ejemplo de inmigración muy precaria que se emprende por mar en embarcaciones tradicionales atravesando el duro canal de la Mona, que separa las islas de La Espańola y Puerto Rico. Una pequeña red de puertorriqueñxs a las que pagaron las personas dominicanas y haitianas desembarcadas en suelo boricua se encargan de transportarlxs, alojarlxs y darles identificaciones pertenecientes a puertorriqueńxs emigradxs a Estados Unidos, complejizando así los circuitos de migración caribeños. Changó, entonces, borrará su nombre y procedencia quisqueyana para poder 
existir a los ojos de la Administración puertorriqueña. Así, su nombre referido a un importante dios de la religión yoruba se esfuma para pasar a llamarse Juan Candelario. Se entiende este hecho como un bautizo blanqueante y cristiano que borra, como lo hicieran los bautizos coloniales, la raíz afrodescendiente, como única forma posible de pertenecer al Estado nación caribeño?.

Entre la red de acogida se encuentra Fabián, un transexual con gustos «raros» que vive una atracción recíproca por Changó. El relato juega con las categorías fluidas y los cambios de nombre, con cómo las identidades fluctúan entre nación, género y sexualidad, y con cómo esta condición de variabilidad es compartida por diversas subjetividades, del aquí y del allí. En este sentido, la frontera política se convierte en una línea agresiva que difumina y permea identidades diversas excluidas del relato oficial de la nación. Además de que la frontera retratada es la de la llegada y la transformación de la persona migrante en falsamente documentada. Arroyo Pizarro indica con ello, con el resto de relatos de Transcaribeñx y con su posicionamiento político expresado en su activismo real y virtual, que nación y género no son categorías estancas, que la realidad del Caribe es una realidad plural, en la que se dan múltiples posibilidades identitarias, lo cual incluye diversos posicionamientos que no pueden ser encerrados en las estructuras castradoras que el patriarcado y la heteronormatividad imponen. María Lugones entiende el heterosexismo como una normatividad perversa por cuanto se impuso de forma violenta a través del modelo colonial de género inaugurando un determinado sistema mundial de poder y dominación («Heterosexualism» 187-188). Este sistema de género siempre presenta implicaciones con la raza, la clase social o la orientación sexual, como se ha expresado ampliamente desde el feminismo negro (Lorde 25; Lugones, «Heterosexualism»188). A su vez, genera varias consecuencias como la división laboral por género, raza y geografía (Lugones, «Heterosexualism» 191) o la condena a sumir en la categorización binaria de masculino/femenino a personas intersexuales (195), imponiéndose con ello a las concepciones sexuales indígenas o nativas no binarias (196).

Yolanda Arroyo Pizarro propone que la libertad política y la sexual son dos aspectos de una misma proclama. En este sentido, el cuestionamiento de los cánones heteropatriarcales, como la monogamia o los roles atribuidos a cada extremo del binario de género, va de la mano con el cuestionamiento del Estado Libre Asociado Puertorriqueño. Nación y género constituyen, entonces, dos instituciones que retroalimentan su prevalencia y, por tanto, perpetúan un sistema de poder. De manera que el camino para la liberación del yo transcurre paralelo al de la liberación de los parámetros sexuales patriarcales y heteronormativos, así como al de la emancipación de un territorio sometido. Se trata de una descolonización total que afecte a

7 Una vez que la potencia norteamericana acapara la soberanía del país boricua, se acentúa la racialización de la población puertorriqueña, como mecanismo de diferenciación cultural que reduce su acceso a la condición de ciudadanía plena (Malavet 22). Este esquema basado en la jerarquía de la raza blanca frente a otras es heredero de la colonialidad del poder articulada a través de la invención de la raza. Así, el blanqueamiento busca reducir la distancia cultural como modo de pertenencia «completa» al Estado nación. 
las esferas del yo, del yo en sus relaciones interpersonales y el yo en su relación con la comunidad. Por consiguiente, encuentra un sentido absoluto con la descolonización del pensamiento, de las prácticas, del conocimiento, del deseo y de la relación con el territorio.

Se produce, así, una interesante conexión entre las demandas por los derechos individuales de comunidades LGBTI y el cuestionamiento del estado neocolonial puertorriqueño. Llevando cotidianamente como lema la máxima utilizada para titular un epígrafe anterior y vinculada en origen al feminismo de que lo personal es político, tal como evidencia expresamente en una publicación en Facebook (Arroyo Pizarro, «Me fascina cuando...»), Arroyo Pizarro comprende como un todo indisoluble lo individual y lo nacional, lo que le atañe a ella y lo que le atañe a lxs demás, con quienes comparte la desprotección sistemática. Lo personal es político para Arroyo Pizarro porque como cuerpo y espiritualidad subalterna, toda acción propia que pretenda subvertir o transgredir el statu quo se convierte en un acto político de resistencia. De ahí que su denuncia sea siempre plural. Valorando y amando su racialidad, combate la negación de la negritud que nace en el Caribe con la colonia y que se ha mantenido bajo diferentes formas de violencia racial a lo largo de los siglos. Denominándose «afrodiva» y admirando sus «afrocurvas» arremete contra la gordofobia de una sociedad que encierra a los cuerpos femeninos en determinados patrones y dimensiones: «Si no tiene una afrodiva de su predilección, use mis afrocurvas para inspirarse. Por cada piropo a una cuerpa como la mía, usted deconstruye los opresivos y crueles estándares de belleza impuestos. Es decir, por cada cumplido a mi hermosa afrogordura, enterramos un poquito más al patriarcado» («Psssst...»). Defendiendo el poliamor, cuestiona los cimientos en los que se ha forjado el amor heterenormativo y la familia tradicional, al mismo tiempo que procede a liberar las corporalidades y las emociones: «afroamarnos, meditar, respirar, besar a otres» («Respirar...»). Descolonizando la espiritualidad, enfoca la mirada hacia religiones afrocaribeńas reprimidas por la preeminencia del catolicismo desde la colonia: «deshonras a tus ancestras cuando practicas la religión de tus opresores» («Las deshonras»).

El signo afro protagoniza la mayor parte de las denuncias de Arroyo Pizarro. El derribo del racismo que ha marcado la historia del Caribe se erige como uno de los objetivos prioritarios en la escritura y el compromiso de la autora. En efecto, la violencia contra lo no blanco legitimada por el sistema colonial encuentra sus consecuencias hasta hoy en día. Los cuerpos negros también se excluyeron en la construcción del Estado nación, por lo tanto, su escritura se convierte en un acto de transformación y de autorreparación. De hecho, la autora habla de afrorreparación y de prietagonismo como estrategias, en lenguaje millennial, que buscan explicar el proceso necesario y negado tradicionalmente, a que las comunidades reconozcan y vivan en plenitud su afrodescendencia. A este objetivo responde su mencionado challenge \#EnnegrecetuProntuario, que secunda los postulados de Sueli Carneiro cuando plantea «ennegrecer el feminismo». Según la filósofa y militante en movimientos sociales, las demandas de las mujeres indígenas y negras en el marco de la lucha antirracista brasileña no pueden ser abordadas únicamente desde el género, sino comprendiendo cuestiones de raza o de clase social (Carneiro 118-119). 
Con similar objetivo, la propuesta de Arroyo Pizarro apela a todas las instituciones educativas puertorriqueñas a incluir en sus guías docentes lecturas de autorxs afrodescendientes. Con la Cátedra de Mujeres Negras Ancestrales de Puerto Rico, un proyecto performático de escritura creativa desde una perspectiva antirracista, pone en valor la negritud, así como la denuncia al racismo sistemático. Todas estas propuestas desembocan en el ansiado saneamiento de la nación frustrada: «Puerto Rico será antirracista o no será» («Exitosa iniciativa...»), escribe en su Facebook.

\section{CONCLUSIONES}

He tratado de demostrar cómo el género autobiográfico encuentra en los formatos de las redes sociales un amplio campo de interactuación a través de la presencia y contenidos vertidos por Yolanda Arroyo Pizarro en Facebook. Su actividad cibernética sucede en consonancia con los presupuestos que guían su obra literaria y el activismo social del que participa. De entre las temáticas relacionadas con la autoescritura, atendí expresamente a aquellas que vinculan realidad personal y realidad nacional, así como el relato de la historia individual y de la historia colectiva, en el marco de las ausencias de las subjetividades afrodescendientes y sexodiversas en el escenario puertorriqueño y, más extensamente, en el del Caribe. Con ello, demuestro cómo la autora utiliza Facebook como un espacio en el que exponer cuestiones vitales que sirven para el cambio epistémico reivindicado, centrado en la superación del racismo y el patriarcado. La escritora puertorriqueña muestra estrategias para reescribir su historia y la Historia desde la negritud y la disidencia sexual, aplicándose a su discurso de análisis o valoración del presente. Su concepción del pasado autocentrado redunda en la concepción autocentrada de su experiencia vital, entendiéndose como fruto de un engranaje de intersecciones. A su vez, su vivencia individual se inserta en una experiencia comunitaria adscrita al proyecto de la nación puertorriqueña de estatuto ambiguo en la actualidad y que reclama una revisión.

De manera que la historia personal que escribe Arroyo Pizarro a través de su diario virtual, centrado en la inclusión de las comunidades vulnerables y en favorecer su representación a través de la literatura, me conduce a aseverar que escribir historias trans y cuir en el marco caribeño contribuye también a escribir la nación deseada, es decir, aquella que incluya todos los cuerpos desde el reconocimiento a su especificidad. Así, aunque descarto que las personalidades retratadas en la ficción puedan ser colocadas en un plano de equivalencia con la propia Arroyo Pizarro, sí considero, a la luz de la ideología comunitaria y combativa de la autora, que la autobiografía trazada incluye, al mismo tiempo, la escritura de la realidad de lxs otrxs. Esta escritura con pretensiones colectivas es concebida en parámetros de sororidad y contribución al reconocimiento de aquellxs que he denominado como los cuerpos excluidos de la escritura de la nación. Ello redunda en múltiples consecuencias de entre las que destaco tres. En primer lugar, en el sentido de comunidad que implica la escritura del yo, por cuanto estx se describe insertx en determinadas dinámicas sociales, culturales e históricas. De entre ellas, he aludido especialmente a aquellas que cuestionan el sentido de nación para el caso de Puerto Rico, dado el racismo, 
el machismo y la heteronormatividad en los que se funda. En segundo lugar, se evidencia la necesidad del diálogo y de la interacción con lxs otrxs para acceder a la autodefinición. Los textos de Arroyo Pizarro revelan la profunda conciencia vivida de este hecho, por ello se esfuerza en retratar a subjetividades cuirs, como la suya propia, que pocas veces se consideran desde la interacción oficial. En tercer lugar, que la construcción de las historias y de las identidades que integran la nación $-\mathrm{y}$ en pequeña escala al yo- están en continuo cambio, en perpetua construcción, y que nunca concluyen pues se generan, precisamente, a través de dichas relaciones. Esto me lleva a secundar una de las más importantes proclamas de la autora y es que categorías tan determinantes en los sistemas de pensamientos en los que se ubican tanto ella como las comunidades vulnerables, como son el género o la nación, no tienen un carácter estático, sino que están sujetas a revisión constante. El problema es que este principio básico rivaliza con la perpetuidad en el poder de ciertos grupos, de ahí que se tengan que buscar estrategias y herramientas para combatir el estatismo, las cuales, claro está, difícilmente pueden proceder de la oficialidad. Arroyo Pizarro, como solución, propone la creación de estructuras genuinas, se reapropia de espacios públicos, como las escuelas o la academia, y aprovecha las posibilidades de lo virtual para hacer de sus acciones cotidianas un referente de sexualidad que busca su autodescolonización y una vivencia de la afroidentidad que camina hacia la autorreparación. 


\section{BIBLIOGRAFÍA}

AnZaldúa, Gloria. Borderlands. La Frontera. The New Mestiza. San Francisco: Aunt Lute Books, 1999.

Aponte-Parés, Luis, Arroyo, Jossianna, Crespo-Kebler, Elizabeth, La Fountain-Stokes, Lawrence y Negrón-Muntaner, Frances. «Puerto Rican Queer Sexualities: Introduction». Centro Journal, 19:1 (Spring 2007), pp. 4-24.

Arfuch, Leonor. «Memoria e imagen». Educação e Realidade, 37:2 (maio-agosto 2012), pp. 399-408.

Arriaga Arango, Eduard. "Yolanda Arroyo Pizarro o la construcción de un cimarronaje electrónico. Hacia una poética electrónica de los marginales». Revista Casa de las Américas, 267 (abril-junio 2012), pp. 24-37, (http://www.casa.co.cu/publicaciones/revistacasa/267/hechosideas.pdf).

Arroyo Pizarro, Yolanda. Lesbianas en clave caribeña. Cuentos de marimachas, buchas y camioneras. Femmes, patas y cachaperas. Barcelona-Madrid: Editorial Egales, 2012.

Arroyo Pizarro, Yolanda. Violeta. Barcelona-Madrid: Editorial Egales, 2014.

Arroyo Pizarro, Yolanda. Transcaribeñx. Barcelona-Madrid: Editorial Egales, 2017.

Arroyo Pizarro, Yolanda. «Seré Makandal...». Facebook, publicado el 31 de julio de 2020, 19:10, (https://www.facebook.com/yolandaarroyopizarro/posts/10163966991825204).

Arroyo Pizarro, Yolanda. "Nuestro país es un gran cómplice de violación sexual». Facebook, 12 de agosto de 2020, 16:53, (https://www.facebook.com/yolandaarroyopizarro/ posts/10164024034810204).

Arroyo Pizarro, Yolanda. «Psssst...». Facebook, publicado el 27 de agosto de 2020, 17:59, (https:// www.facebook.com/yolandaarroyopizarro/posts/10164083008920204).

Arroyo Pizarro, Yolanda. «Respirar...». Facebook, publicado el 27 de agosto de 2020, 21:08, (https:// www.facebook.com/yolandaarroyopizarro/videos/10164083724780204).

Arroyo Pizarro, Yolanda. «Camino al campo de Caguas...». Facebook, publicado el 13 de septiembre de 2020, 12:34, (https://www.facebook.com/yolandaarroyopizarro/posts/10164151416435204).

Arroyo Pizarro, Yolanda. «Me fascina cuando la gente...». Facebook, 27 de septiembre de 2020, 01:48, (https://www.facebook.com/yolandaarroyopizarro/posts/10164204860950204).

Arroyo Pizarro, Yolanda. «Las deshonras». Facebook, 1 de octubre de 2020, 12:49, (https://www. facebook.com/yolandaarroyopizarro/posts/10164221542920204).

Arroyo Pizarro, Yolanda. «Exitosa iniciativa...». Facebook, 1 de octubre de 2020, 19:06, (https:// www.facebook.com/yolandaarroyopizarro/videos/10164222728895204).

Arroyo PiZarro, Yolanda. «12 de octubre». Facebook, 12 de octubre de 2020, 06:41, (https://www. facebook.com/yolandaarroyopizarro/videos/10164263922115204).

Arroyo Pizarro, Yolanda. «Somos la novela puertorriqueña...». Facebook, 1 de diciembre de 2020, 15:00, (https://www.facebook.com/yolandaarroyopizarro/posts/10164454817580204).

Arroyo Pizarro, Yolanda. «Los hombres caciques...». Facebook, 19 de enero de 2021, 23:24, (https:// www.facebook.com/yolandaarroyopizarro/posts/10164645556630204).

Barradas, Efraín. «Sirena selena vestida de pena o el Caribe como travestí». Centro Journal, 15:1 (Spring 2003), pp. 53-65.

Benítez Rojo, Antonio. La isla que se repite. Puerto Rico: Plaza Mayor, 2010. 
Calzati, Stefano y Simanowski, Roberto. «Self-Narratives on Social Networks. Trans-Platform Stories and Facebook's Metamorphosis into a Postmodern Semiautomated Repository». Biography, 41:1 (Winter 2018), pp. 24-47. DOI: http://doi.org/10.1353/bio.2018.0007.

Capote Cruz, Zaida. La nación intima. La Habana: Ediciones Unión, 2008.

Carneiro, Sueli. «Mulheres em movimento». Estudos Avançados, 17:49 (2003), pp. 117-132, http:// dx.doi.org/10.1590/S0103-40142003000300008.

Castro Gómez, Santiago y Grosfoguel, Ramón (eds.). El giro decolonial. Reflexiones para una diversidad epistémica más allá del capitalismo global. Bogotá: Siglo del Hombre Editores-Universidad Central-Pontificia Universidad Javeriana, 2007.

Curiel, Ochy. «El régimen heterosexual y la nación. Aportes del lesbianismo feminista a la antropología». La manzana de la discordia, 6:1 (enero-junio 2011), pp. 25-46. DOI: http://dx. doi.org/10.25100/lamanzanadeladiscordia.v6i1.1507.

Espınosa Mıñoso, Yuderkys. «Historizar las disputas, indagar las fuentes: hipótesis para pensar el movimiento de lesbianas en América Latina». Atlánticas-Revista Internacional de Estudios Feministas, 1:1 (2016), pp. 240-259. DOI: http://dx.doi.org/10.17979.

Espinosa Miñoso, Yuderkys. «Hacer genealogía de la experiencia: el método hacia una crítica a la colonialidad de la Razón feminista desde la experiencia histórica en América Latina». Revista Direito e Praxis, 10:3 (2019), pp. 2007-2032. DOI: https://doi.org/10.1590/21798966/2019/43881.

Falconí Trávez, Diego. «Puerto Rico erizando mi piel. Intertextos/intercuerpos lordeanos en la narrativa de Yolanda Arroyo Pizarro». Letras femeninas, 42:1 (2016), pp. 55-73.

FAnON, Frantz. Les damnés de la terre. Paris: La Découverte, 2002.

Fanon, Frantz. Peau noire, masques blancs. Paris: Éditions du Seuil, 1971.

Foucault, Michel. L'archéologie du savoir. Paris: Gallimard, 1969.

Foucault, Michel. Histoire de la sexualité 1. La volonté de savoir. Paris: Gallimard, 1976.

García Muñiz, Humberto. "The Colonial Persuasion. Puerto Rico and the Dutch and French Antilles», en Palmié, Stephan y Scarano, Francisco A. (eds.), The Caribbean: a history of the region and its people, Chicago-Londres: The University of Chicago Press, 2011, pp. 537-551.

Glissant, Édouard. Introduction à une poétique du Divers. Paris: Gallimard, 1996.

Guadalupe De Jesús, Raúl. El evangelio de Makandal y los hacedores de la lluvia: ensayos sobre literatura, historia y politica del Caribe. Puerto Rico: Editorial Tiempo Nuevo, 2015.

Quijano, Aníbal. «Colonialidad del poder y clasificación social», en Cuestiones y horizontes: de la dependencia histórico-estructural a la colonialidad/descolonialidad del poder, Buenos Aires: CLACSO, 2014, pp. 285-327. https://core.ac.uk/download/pdf/35166683.pdf.

Hill Collins, Patricia y Bilge, Sirma. Intersectionality. Medford: Polity Press, 2020.

La Fountain-Stokes, Lawrence y Martínez-San Miguel, Yolanda. «Revisiting Queer Puerto Rican Sexualities: Queer Futures, Reinventions, and Un-Disciplines Archives-Introduction». Centro Journal, 30:2 (Summer 2018), pp. 6-41.

LARGE, Sophie. «El activismo queer, feminista y decolonial en la literatura de Yolanda Arroyo Pizarro: por un pensamiento de la Relación». Centro Journal, 30:2 (Summer 2018), pp. 254-271.

Lladó Ortega, Mónica C. «El cuerpo y la praxis del flujo en la narrativa de Yolanda Arroyo Pizarro». Centro Journal, 30:2 (Summer 2018), pp. 272-294. 
Lorde, Audre. «The Master's Tool Will Never Dismantle the Master's House», en Lewis, Reina y Mills, Sara (eds.), Feminist Postcolonial Theory. A Reader, New York: Routledge, 2003, pp. 25-28.

Lugones, María. «Heterosexualism and the Colonial /Modern Gender System». Hypatia, 22:1 (Winter 2007), pp. 186-209. DOI: https://doi.org/10.1111/j.1527-2001.2007.tb01156.x.

Lugones, María. «Colonialidad y Género». Tabula Rasa, 9 (julio-diciembre 2008), pp. 73-101. DOI: https://doi.org/10.25058/20112742.340.

Malavet, Pedro A. America's Colony. The Political and Cultural Conflict between the United States and Puerto Rico. Nueva York: New York University Press, 2004.

MCneill, Laurie. "There Is No "I" in Network: Social Networking Sites and Posthuman Auto/ biography». Biography, 35:1 (Winter 2012), pp. 65-82. DOI: https://doi.org/10.1353/ bio.2012.0009.

Mezilas, Glodel. El trauma colonial. Entre la memoria y el discurso. Pensar (desde) el Caribe. Pompano Beach: Educa Vision, 2015.

Ortiz SÁnChez, Luz Marilyn. «Cuerpos e identidades on line: construcción de identidades corporales en el chat». Colombian Applied Linguistic Journal, 15:2 (junio-diciembre 2013), pp. 302309. DOI: http://dx.doi.org/10.14483/udistrital.jour.calj.2013.2.a011.

Rangelova, Radost. "Nationalism, States of Exception, and Caribbean Identities in Sirena Selena vestida de pena and "Loca la de la locura”. Centro Journal, 19:1 (Spring 2007), pp. 75-88.

SPIVAK, Gayatri Chakravarty. «Puede hablar el subalterno?». Revista Colombiana de Antropología, 39 (2003), pp. 296-364.

VAldez, Elena. «Visibilizando la sexodiversidad: el contrapunteo de la mononormatividad y los poliamores en Violeta, de Yolanda Arroyo Pizarro». Centro Journal, 30:2 (Summer 2018), pp. 296-319.

WArner, Michael. The Trouble with Normal. Sex, Politics, and the Ethics of Queer Life. Cambridge: Harvard University Press, 2000. 